\title{
Comunicação pública da Ciência diante das coalizões em conflito sobre aquecimento global
}

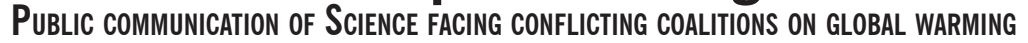 \\ Maria José da Costa Oliveira', Ronaldo Barbosa ${ }^{2,3}$, Celso Dal Ré Carnelro $0^{2,4}$, Helooza Matos e Nobre ${ }^{5}$ \\ 1 - Grupo de pesquisa em Comunicação Pública e Política (Compol), Escola de Comunicaçōes e Artes (ECA), Universidade de São Paulo (USP), São Paulo, SP, \\ BRASLL. \\ 2 - Docente do Programa de Pós-Graduação em Ensino e História de Clências da Terra, (PPG-EHCT), Instituto de Geociências (IG), Universidade Estadual de \\ Campinas (Unicamp), Campinas, SP, Brasil. \\ 3 - Docente do Instituto de Artes (IA), Universidade Estadual de Campinas (Unicamp), Campinas, SP, Brasil. \\ 4 - PESQUISADOR CNPQ. \\ 5 - Docente da Escola de Comunicaçōes e Artes (ECA), Universidade de São Paulo (USP), São Paulo, SP, Brasil.

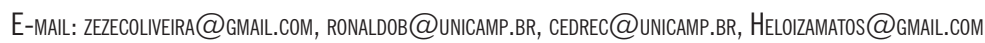

Abstract: Science public communication is a highly relevant factor in the formulation of public sustainability policies. Applying the model of the Advocacy Coalition Framework (ACF), we seek to illuminate the disputes and controversy in the debate regarding the issue of anthropogenic global warming. Different coalitions around the "Climate change" theme decisively participate in disputes and conflicts. However, there are controversial and irresponsible manipulations, as well as unfair ones, formed mainly by fake news, which weaken the citizens' posture and prevent the formation of a critical conscience about this and other controversial topics. In scenarios that are not prone to consensus, it is necessary to move from antagonism to agonism, when coalitions tend to abandon the "us" / "them" antagonism and no longer question the legitimacy of the actors in conflict. It is concluded that certain fragile speeches, supported by false news, cause damage to society, the environment and the very quality of democracy.

Citation/Citação: Oliveira, M. J. C., Barbosa, R., Carneiro C. D. R., \& Nobre, H. M. e. (2021). Comunicação pública da Ciência diante das coalizões em conflito sobre aquecimento global. Terræ Didatica, 17(Publ. Contínua), 1-13, e021011. doi: 10.20396/td.v17i0.8663967.

\begin{abstract}
Keywords: Sustainability. Climate change. Uncertainty. Social Communication of Science. Science and Public Audiences.
\end{abstract}

Resumo: A formulação de políticas públicas de sustentabilidade apoia-se de maneira decisiva na Palavras-chave: Sustentabilidade. Mudancomunicação pública da Ciência. Aplicando o modelo da Advocacy Coalition Framework (ACF) os autores deste artigo buscam iluminar as disputas sobre a questão do aquecimento global antropogênico e a controvérsia existente. Distintas coalizões em torno do tema "mudança climática" participam decisivamente das disputas e do conflito. Contudo, existem manipulações polêmicas e irresponsáveis, além de desleais, formadas sobretudo por fake news, que fragilizam a postura dos cidadãos e impedem a formação de uma consciência crítica sobre esse e outros temas polêmicos. Em cenários pouco propensos ao consenso, é necessário avançar do antagonismo para o agonismo, quando as coalizões tendem a abandonar 0 antagonismo "nós" / "eles" e não mais questionam a legitimidade dos atores em conflito. Conclui-se que certos discursos frágeis, respaldados em notícias falsas, geram prejúízos à sociedade, ao meio ambiente e à própria qualidade da democracia.

ça Climática. Incerteza. Comunicação Social da Ciência. Ciência e Públicos.

\section{Manuscript/Manuscrito:}

Received/Recebido: 18/01/2021

Revised/Corrigido: 02/02/2021

Accepted/Aceito: 23/02/2021

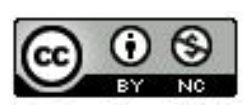

\section{Introdução}

A concepção sistêmica da Terra identifica amplas interconexões dos sistemas vivos, ao mesmo tempo em que reconhece a existência de profunda interdependência dos integrantes do meio biótico em relação ao meio abiótico. Admitindo-se que a ideia possa ser aplicada a muitas questões sociais, energéticas, econômicas e ambientais, é viável adotar uma perspectiva sistêmica para relacionar comunicação e meio ambiente, na medida em que a comunicação, além de ser uma capacidade intrínseca aos seres humanos, é fator básico para impulsionar a evolução das sociedades, permitindo intercambiar experiências e, ao mesmo tempo, adquirir e compartilhar conhecimento:

\begin{abstract}
(...) a circulação do conhecimento científico na universidade, na escola e na sociedade, é uma questão central para se pensar nos rumos de uma universidade para o século XXI e no mundo que queremos construir. Central, mas bastante opaca (Silva, 2008, p. 9).
\end{abstract}

A Ciência é um modo de "observar, pensar e agir no mundo" em que vivemos, uma ferramenta utilizada para melhorar a vida das pessoas e sistematizar seus conhecimentos (Lindley, 2006). Nessa visão, Ciência é sobretudo

(...) um método, reconhecidamente um método que tem sido mais bem-sucedido nos campos 
que normalmente consideramos científicos e menos nas artes, mas tem o potencial de ser empregado em qualquer lugar (Lindley, 2006, p.186).

Um corolário dessa concepção é o reconhecimento de que a Comunicação Pública da Ciência tem efeitos diretos no estabelecimento de políticas públicas de sustentabilidade. Oliveira et al. (2020) analisam o impacto da comunicação pública da Ciência como parte integrante da formulação de políticas públicas. Os autores aplicam a matriz teórica e metodológica da $A d$ vocac ${ }^{1}$ Coalition Framework $(\mathrm{ACF})^{2}$, proposta nos anos 1980 e aprimorada desde então (Sabatier, 1988, Sabatier \& Jenkins-Smith, 1999), para analisar a maneira pela qual diferentes coalizões se formam e se colocam em disputa para influenciar determinada política pública (Sabatier \& Weible, 2007) (Fig. 1). No caso em pauta, foi selecionado como objeto de estudo, dentro do contexto da sustentabilidade, o Aquecimento Global Antropogênico (AGA), por concentrar pontos de vista antagônicos, convergentes e neutros, passíveis de serem analisados por meio do modelo ACF. $\mathrm{O}$ conceito de AGA está diretamente vinculado à concepção de mudança climática, um campo interdisciplinar de pesquisas que é objeto de investigação intensiva no mundo da Ciência e de acalorado debate nos mais diversos veículos de comunicação.

O reconhecimento de que existe um componente de aquecimento global criado pelo homem (Lomborg, 2002, p. 312) não implica aceitar sem crítica muitas previsões e cenários exagerados que têm sido construídos a respeito das condições do clima futuro. A questão tem relação direta com o dilema do acesso ao conhecimento científico pela

1 Processo organizado e planejado de informar e influenciar tomadores de decisão por meio de conscientização e engajamento de outros atores da sociedade, tendo como objetivo promover mudança ou manutenção de uma política pública de interesse amplo, com base em evidências concretas (Gozetto \& Machado, 2015).

20 Advocacy Coalition Framework (ainda sem tradução precisa) é um quadro analítico utilizado para analisar o processo de formulação de políticas públicas, sendo utilizado como metodologia que permite identificar de que forma agrupamentos concorrentes de grupos e indivíduos (advocacy coalitions) competem por políticas "vencedoras" em um determinado subsistema, usando estratégias políticas para afetar favoravelmente decisões, bem como informações técnicas e científicas, para mudar pontos de vista de outras coalizões (Sabatier, 1988). sociedade. Os termos vulgarização, alfabetização, divulgação e popularização da Ciência relacionam-se, todos eles, ao acesso orgânico e articulado ao conhecimento. Se partirmos do entendimento de que "alfabetização científica" é "a capacidade de ler, compreender e expressar opinião sobre assuntos de caráter científico" (Germano \& Kulesza, 2007), indivíduos alfabetizados na Ciência do clima são aqueles capazes de entender a importância das observações, dos registros climáticos e da modelagem na interpretação do clima. Conscientes da relação fundamental entre o clima e a vida humana, tais indivíduos têm a capacidade de avaliar a validade dos argumentos científicos sobre o clima e usar tal informação para apoiar suas convicções e decisões (Oliveira, Vecchia \& Carneiro, 2015, p. 293), sem sofrer influência de notícias inverídicas.

Este estudo objetiva aplicar a metodologia ACF para analisar a argumentação e os recursos utilizados por diferentes coalizões que se formaram em torno do aquecimento global antropogênico, e que impactam as políticas públicas com foco nas mudanças climáticas. Termos e expressões como "sustentabilidade" e "mudança climática" são usados de várias maneiras na literatura científica. Assim, para maior clareza, fornecemos e justificamos resumidamente as definições adotadas na presente revisão.

A contribuição pretende dar continuidade ao debate, levantando aspectos do conflito de ideias e modelos teóricos apresentados, em função sobretudo da intensificação das fake news ${ }^{3}$ (notícias falsas ou

3 A expressão "Fake News" (termo em inglês que designa notícias falsas) é relativamente contraditória, pois, se é fake não deveria ser News; e se é News, deveria ser necessariamente verdadeira, jamais fake. Mas a expressão se refere, antes, ao intuito com que se "compra ou vende" a notícia: quem oferece, sabe que é falsa, mas quer fazer parecer que é verdadeira; e quem compra, acha que é verdadeira, ainda que devesse checar se é falsa ou não. Há, então, uma realidade dupla: a do estatuto real da notícia em si (se é originalmente falsa ou verdadeira), e a da forma como se publiciza a notícia nas trocas comunicacionais, independente do estatuto real da mesma. Ou seja, uma realidade, que se refere ao fenômeno em si, é uma realidade humana na disposição que se faz do fenômeno. Mas, é preciso esclarecer: uma News, no sentido de material jornalístico apurado e checado, é, por definição, verdadeira - ainda que contingente, isto é, dentro de um contexto específico. Se o sentido de "fake news" está centrado na falsidade em primeiro lugar, existe apenas a intenção de se passar enganosamente como tal; e isso se dá sempre com o objetivo de atingir um fim nefasto: prejudicar um indivíduo, uma empresa, um partido, uma ideia, 


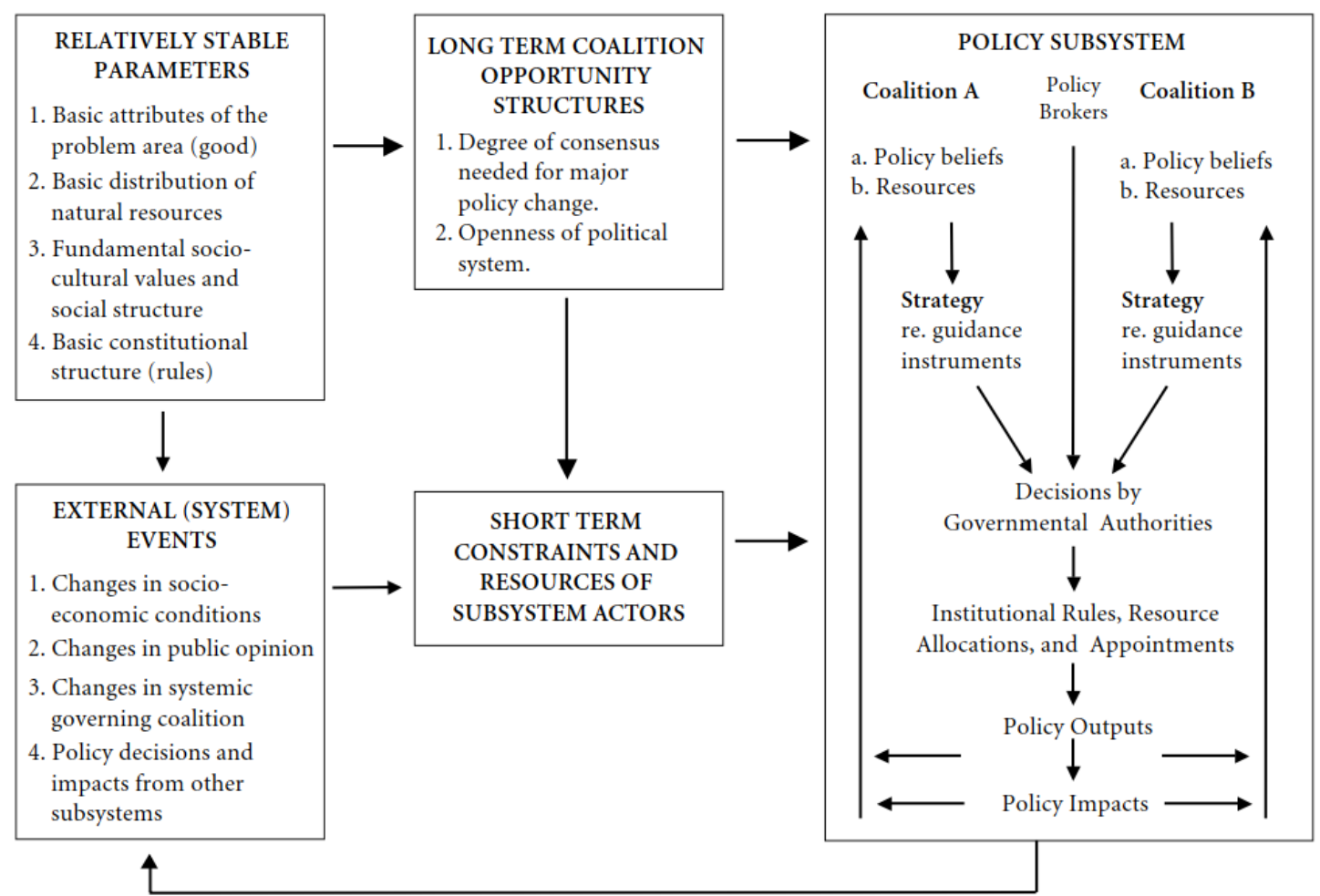

Figura 1. Diagrama original da Advocacy Coalition Framework, versão de 2005. Fonte: Sabatier \& Weible (2007, p. 202)

enganosas) que, nos últimos anos, alteraram radicalmente o cenário de discussão no âmbito de AGA, dentre tantas questões candentes. A circulação de fake news pode ser altamente negativa para a formação de uma corrente de opinião consistente a respeito de AGA, uma vez que pode confundir o receptor da mensagem, até mesmo diante da incerteza presente em cada modelo científico. O prejuízo pode ser ainda mais grave, se o receptor estiver interessado em saber se os conceitos envolvidos são adequados ou equivocados. A incerteza é um componente inescapável da Ciência (Lindley, 2006).

\section{Sustentabilidade}

A Agenda 2030 para o Desenvolvimento Sustentável, adotada pelos Estados-Membros das Nações Unidas, compreende 17 Objetivos de Desenvolvimento Sustentável (ODS) e 169 Metas. A resolução é "um plano compartilhado para a paz e a prosperidade das pessoas e do planeta, agora e no futuro" (UN/DESA/DSDG, 2015) que busca estabelecer uma parceria global para garantir a sus-

um projeto, e até um conceito científico. Ao contrário da News jornalística, que deve servir aos cidadãos e promover o bem estar público, como recurso político duvidoso ou falso, a fake News, no sentido amplo, existe para minar, prejudicar, impedir, ferir, eliminar um conceito verdadeiro da comunicação e da Ciência. tentabilidade das atividades humanas no planeta. Ao definir como principal desafio global a erradicação da pobreza em todas as formas e dimensões, incluindo a pobreza extrema, o documento clama pela atuação efetiva dos países desenvolvidos e em desenvolvimento, cujas ações devem incluir estratégias que melhorem a saúde e a educação, reduzam a desigualdade e estimulem o crescimento econômico, junto com a preservação de oceanos e florestas e o enfrentamento às mudanças climáticas (UN/DESA, s.d.).

O conceito de Desenvolvimento Sustentável (DS) foi cunhado em 1987 pelo relatório Our Common Future da World Commission on Environment and Development (UN/WCED, 1987), que ficou conhecido como Relatório Brundtland, em referência à chairman da comissão, a primeira-ministra da Noruega, Gro Harlem Brundtland.

A humanidade tem a capacidade de fazer desenvolvimento sustentável para garantir o atendimento das necessidades do presente sem comprometer a capacidade de as futuras gerações atenderem às suas próprias necessidades (UN/ WCED, 1987, p.11).

Inserido na agenda política, o conceito DS foi amplamente difundido desde a conferência "Cúpula da Terra" no Rio de Janeiro, Brasil, em junho de 
1992, quando mais de 178 países adotaram a Agenda 21, um plano de ação abrangente para coordenar ações dos diferentes países em favor do desenvolvimento sustentável, da melhoria da vida humana e da proteção ao meio ambiente (Martins et al., 2015). Em 2013, a Assembleia Geral das Nações Unidas criou um Grupo de Trabalho Aberto de 30 membros para desenvolver uma proposta sobre os Objetivos de Desenvolvimento Sustentável. A proposta foi aprovada em setembro de 2015, na Cúpula do Desenvolvimento Sustentável da ONU em Nova York, quando os 17 objetivos compuseram o núcleo do documento Transforming our world: Agenda 2030 para o Desenvolvimento Sustentável. O ODS de número 13 refere-se às mudanças climáticas, tendo sido fundamental para a aprovação, em dezembro de 2015, do Acordo de Paris sobre Mudanças Climáticas. O objetivo 13 tem a seguinte redação: Tomar medidas urgentes para combater as mudanças climáticas e seus impactos (UN/DESA/DSDG, 2015).

\section{Mudança Climática}

O clima terrestre resulta basicamente do funcionamento de "um sistema incrivelmente complexo" (Lomborg, 2002, p. 320), controlado pela troca de energia entre a Terra, o Sol e o espaço exterior, e que envolve cinco grandes componentes terrestres: a atmosfera, os oceanos, as terras emersas, a biosfera e a criosfera (mantos de gelo); assim, o clima das diferentes regiões do planeta é determinado por variáveis que definem o estado geral da atmosfera: temperatura; pressão; direção e intensidade dos ventos; umidade e precipitação. A visão sistêmica da Geologia acentua a importância de se conhecer a interação de agentes que redistribuem o calor e a umidade em superfície, tendo como principal fator natural a energia gerada pelo Sol, que controla o balanço de entrada e saída de radiação na Terra.

O aquecimento global é uma possibilidade aberta pelas cíclicas mudanças do clima terrestre. Quando se fala em mudança climática é indispensável envolver o fator tempo, pois as alterações resultam da interação continuada de fatores naturais ou antrópicos que modificam os componentes do balanço de radiação terrestre, ao longo de escalas de tempo da ordem de séculos, milênios ou até mesmo milhões de anos (Oliveira, Vecchia \& Carneiro, 2017). Os padrões mundiais de clima são determinados por conjuntos de fatores astronômicos, geológicos e atmosféricos. Abundantes evidências e comprovações de que o clima terrestre incessantemente se modifica integram o moderno conhecimento da história geológica da Terra.

Pesquisas modernas focalizam pormenorizadamente o modo de funcionamento das peças que compõem o quebra-cabeças do clima. O estudo dos eventos extremos de precipitação, que podem alterar profundamente a disponibilidade hídrica, a silvicultura, a produção de energia e a agricultura, entre outros (Reboita et al., 2018), fazem parte da tendência de se investigar padrões de magnitude continental. Uma das finalidades é determinar a validade da hipótese levantada pelo IPCC (2013) de que a "frequência, magnitude e duração dos eventos extremos chuvosos têm aumentado em décadas recentes em diversas regiões do globo e são projetados a aumentar no futuro" (Marrafon \& Reboita, 2020). Os autores, contudo, assinalam que a atmosfera não é estática:

(...) os ventos, por exemplo, contribuem para o transporte de umidade de uma região a outra. Fato que pode explicar, em parte, porque a precipitação não aumenta em todo o globo da mesma forma que ocorre em relação à temperatura (Marrafon \& Reboita, 2020, p.664).

No debate acerca de aquecimento global antropogênico, entretanto, conceitos e informações sobre o registro geológico permanecem escassos (Carneiro \& Toniolo, 2010), sendo muitas vezes esquecidas ou omitidas as causas naturais e até mesmo a notável alternância de épocas frias e quentes no passado remoto. Não se pode esquecer que, ainda em tempos históricos, a humanidade vivenciou condições climáticas mais frias, como o intervalo global conhecido como Pequena Idade do Gelo (PIG), durante o final da Idade Média e início da Idade Moderna (Carneiro et al., 2018, 2020). Pesquisas sobre esse prolongado intervalo de tempo possibilitam aprofundar e caracterizar mais adequadamente os fatores que determinam as oscilações do clima mundial.

\section{Comunicação Pública da Ciência}

A comunicação que atende ao interesse público e nele se fundamenta, denominada "Comunicação Pública” $(\mathrm{CPu})$, precisa ser ao mesmo tempo sistêmica, articulada e democrática, além de envolver diferentes atores sociais. A CPu é realizada por "atores sociais emergentes na esfera pública com capacidade para debater e formular propostas em face dos apelos das campanhas institucionais" (Matos, 
2006, p.61). Em contraposição, a "Comunicação Política" (CPo) é concebida como um "conjunto de técnicas usadas por políticos e governantes para seduzir e manipular a opinião pública" (Matos, 2006, p.67), segundo um processo competitivo interativo, que modernamente inclui "a troca de informações" entre atores políticos, os veículos de mídia e o público. $\mathrm{Na}$ atualidade, o variado leque de recursos de comunicação e as mudanças nos padrões de engajamento cívico dos cidadãos exigem que "as estratégias e políticas de comunicação organizacional levem em conta as demandas públicas" (Oliveira, 2013, p.15).

Ademais, o avanço tecnológico acelerou a circulação de informações e ideias, amplificando o debate, ao disseminar velozmente, em tempo real, relatos e imagens sobre fatos ocorridos em todo o mundo (Vilaça, 2012). Por outro lado, "a Internet funciona com base na confiança, mas sua dependência da confiança também abre várias vulnerabilidades" (Morozov, 2011, p.148). O emprego de mecanismos de falseamento por alguns atores não constitui, de modo algum, um mecanismo de livre contraponto de ideias ou modelos, pois tem o vício de deformar fortemente tanto o resultado correspondente quanto o impacto efetivo das políticas públicas. Pode-se avaliar a relevância das fake-news tanto pela intensidade quanto pela frequência com que elas emergem nos diversos veículos de comunicação social. Ao mesmo tempo em que semeiam divergências, geram desconfiança e comprometem a formação de uma consciência crítica sobre questões polêmicas como AGA (Oliveira et al., 2020).

Quando o discurso científico se afasta da população, abre-se margem para distintas percepções, diante do impacto direto (ou impactos futuros em potencial) sobre cada indivíduo. Embora seja muito grande o volume de pesquisas que focalizam AGA, parece ser justificável mensurar até que ponto os resultados dos estudos são divulgados por formas de comunicação capazes de alcançar a sociedade em geral e fornecer elementos passíveis de compreensão, para enriquecer o debate. Para que a mensagem atinja o receptor, é preciso haver afinidade entre os interesses do receptor e do emissor, além de certa confiabilidade (Castells, 2009). Além disso, é preciso considerar, conforme indica Caldas (2004, p. 30 ), que o avanço científico e tecnológico brasileiro não é acompanhado de uma mudança cultural sobre o papel que Ciência, Tecnologia \& Inovação (CT\&I) ocupam na melhoria da qualidade de vida e na produção de conhecimento crítico para pro- mover transformação social.

O distanciamento em relação à sociedade cria espaço para argumentações desprovidas de comprovação científica, porém bastante eficazes no ato de tornar comum determinada a ideia ou posição que se procura defender. Ao alertar sobre os impactos da cisão entre discurso científico e sociedade, Caldas (2004, p. 31) sugere que a compreensão pública da Ciência deva ir além do conhecimento específico dos conteúdos. Tal perspectiva é compartilhada por Santos \& Fonseca (2019, p.292), que enfatizam a importância da construção adequada de conteúdo e do diálogo com a sociedade, em detrimento da simples transmissão da mensagem científica, assim como defende Freire ao mencionar que:

Só se comunica o inteligível na medida em que este é comunicável. Esta é a razão pela qual, enquanto a significação não for compreensível para um dos sujeitos, não é possível a compreensão do significado ao qual um deles já chegou e que, não obstante, não foi apreendida pelo outro na expressão do primeiro (Freire, 1975, p. 68).

Uma vez que aqui também é realizada uma análise com base no diagrama ACF (Advocacy Coalition Framework), é necessário reforçar a defesa de Jaramillo López quanto à comunicação pública em seu aspecto de advocacy, que privilegia a mobilização para a sensibilização a respeito de questões de interesse geral. Advocacy, ou advocacia, é mobilização social. Portanto, é uma ação de comunicação e, mais especificamente, de comunicação pública. Trata-se de uma estratégia de se convocar e construir propósitos comuns, com o objetivo de produzir significado e sentido compartilhados em assuntos de interesse coletivo (Jaramillo López, 2011a, p. 62).

Interessa à finalidade deste artigo analisar o fenômeno que vem impactando temas que pareciam ter alcançado certo consenso, e que hoje apresentam posições negacionistas, como é o caso da rejeição a campanhas de vacinação, modelos "terraplanistas", dentre tantos outros. Afinal, em sociedades cada vez mais complexas e diversas, o alcance atual das discussões nas redes sociais pode desconstruir cenários de compreensão e postura mais responsável sobre temas de interesse público.

\section{Consenso e antagonismo}

O tema do aquecimento global antropogênico está umbilicalmente ligado à ideia de sustentabilidade ambiental e tem, portanto, interesse público

\begin{tabular}{c|c|c|c|c|c}
\hline (C) Terrae Didat. & Campinas, SP & v.17 & $1-11$ & $\mathrm{e} 021011$ & 2021 \\
\hline
\end{tabular}


direto, mas a comunicação pública dos resultados das pesquisas e das concepções diretamente relacionados ao tema constitui um imenso desafio para a Ciência e para os cientistas. Para a proposta de se estudar a questão do diálogo e do consenso na Comunicação Pública da Ciência, a linguagem passa a ser um instrumento fundamental "para alcançar consensos envolvendo a totalidade dos atores sociais" (Oliveira et al., 2020, p.5).

$\mathrm{O}$ crescimento das redes sociais, nas quais diferentes vozes podem se expressar, sem, no entanto, haver predisposição ao diálogo, cria obstáculos à proposição de Habermas (2008), para quem a validação dos argumentos pelo debate é uma condição prévia à tomada de decisões, e pressupõe a busca de entendimento e consenso. Entretanto, nas atuais disputas por hegemonia, o conflito parece ser um elemento fundamental e absolutamente necessário (Mouffe, 2015). Essa autora valoriza o campo discursivo como sendo inerente à noção de democracia, e admite a possibilidade de se levar a discussão pública a extremos, até que se encontre uma saída radical para o antagonismo entre os adversários políticos, capaz de transformá-lo em agonismo.

Enquanto o antagonismo é uma relação nós/ eles em que os dois lados são inimigos que não possuem qualquer ponto em comum, o agonismo é uma relação nós/eles em que as partes conflitantes, embora reconhecendo que não existe nenhuma solução racional para o conflito, ainda assim reconhecem a legitimidade de seus oponentes. Eles são "adversários", não inimigos. Isso quer dizer que, embora em conflito, eles se consideram pertencentes ao mesmo ente político, partilhando de um mesmo espaço simbólico dentro do qual tem lugar o conflito. Poderíamos dizer que a tarefa da democracia é transformar antagonismo em agonismo (Mouffe, 2015, p.19).

Tais pressupostos teóricos indicam a relevância de se entender como é feita a argumentação em torno de temas de interesse público, como o aquecimento global. Do mesmo modo, acentuam a importância de se usar tecnologia para identificar as chamadas Fake News, visando assegurar que o agonismo se realize diante de argumentos válidos, que assegurem confiabilidade e legitimidade (Monteiro et al., 2018). Porém, antes de avançar na análise sobre a validade dos argumentos, cabe situar brevemente as diferentes posi- ções existentes a respeito do aquecimento global antropogênico.

[A Geologia] não teria qualquer interesse científico se a Terra não tivesse sido afetada no passado por mudanças ambientais (van Loon, 1999).

\section{0 alarmismo sobre aquecimento global}

Há pouco mais de uma década, diversos trabalhos, relatórios e artigos científicos propunham a existência de um consenso (Anderegg et al., 2010) quanto às causas e efeitos do AGA, sob a perspectiva de que a Terra estivesse se aquecendo em velocidade cada vez mais acelerada, em decorrência de emissões de gases de efeito estufa gerados pela atividade humana. Contudo, o suposto consenso passou a ser contestado de modo crescente. Se o tema for analisado sob o ponto de vista da comunicação pública, ficará cada vez mais claro que as diferentes percepções, discussões e embates múltiplos envolvem questões de interesse público, a exemplo de muitos outros temas que são objeto de disputa no contexto da comunicação pública. Oliveira et al. (2020) visualizam tal fenômeno como um exemplo de comunicação pública, ou seja, uma comunicação sobre temas de interesse público, que constitui uma possibilidade real de debate na arena pública. Em outros termos, exige-se que a divulgação da Ciência seja praticada da forma mais ampla e precisa possível, porque ela é um dos grandes desafios do século XXI: "se queremos realmente uma sociedade democrática, é preciso que todos entendam a Ciência. Caso contrário, não alcançaremos a democracia cultural" (Hernando, 2005).

\footnotetext{
Seria essa a essência da comunicação e da tecnologia voltada para promover desinformação sobre questões ligadas à sustentabilidade e tantas outras de interesse público? Estariam os sujeitos da sociedade atual preparados para discernir entre o que é falso e o que é verdade? Ao mesmo tempo, estariam os sujeitos abertos a ouvir os argumentos válidos daqueles que se contrapõem a suas posições? (Oliveira et al., 2020, p.3).
}

Podemos concluir que o uso frequente de fake news pode influenciar opiniões e tornar cada vez mais generalizado um clima de desconfiança. 


\section{Diferentes coalizões no debate sobre AGA}

A discussão a respeito do aquecimento global perdeu intensidade no panorama atual de preocupações com o COVID-194, não obstante continue a compor uma arena de intenso debate, com posturas antagônicas que disputam influência direta nas políticas públicas de sustentabilidade. Levantamento realizado por Oliveira et al. (2020), acerca das diferentes posições que se apresentam sobre o aquecimento global, identificou as seguintes coalizões:

1. "O aquecimento global existe e é culpa do homem": constitui a argumentação predominante no meio científico e a mais frequente nos veículos de comunicação. A corrente apoia-se na influência dos chamados gases-estufa, que controlam o fenômeno natural do "efeito estufa”, responsável pela manutenção do calor na Terra graças à retenção de energia (calor) trazida pelos raios solares. Os defensores baseiam-se em relatórios do Painel Intergovernamental de Mudanças Climáticas (IPCC), órgão ligado à Organização das Nações Unidas (ONU), cujos relatórios são "a base da maioria das políticas públicas sobre mudanças climáticas e da maioria dos argumentos apresentados pelas organizações ambientais" (Lomborg, 2002, p.313). Sucessivos relatórios do IPCC fazem diversas previsões apocalípticas sobre: iminente fusão das calotas de gelo polar; destruição de ecossistemas; elevação do nível médio dos oceanos e consequente inundação de cidades costeiras; incidência de eventos climáticos intensos; desertificação de grandes extensões de terras aráveis, com efeitos diretos na produção de alimentos. A explanação restritiva de que os gases-estufa liberados pela ação humana na atmosfera provocam a oscilação do clima moderno sustenta a interpretação de que a elevação da temperatura média do planeta resulta do crescimento das taxas de emissão de gases como o gás carbônico $\left(\mathrm{CO}_{2}\right)$, que intensificam o efeito estufa. Cerca de $90 \%$ das alterações climáticas teriam sido causadas pelo homem e apenas $10 \%$ seriam naturais. Nessa perspectiva, "gases antropogênicos de efeito estufa foram responsáveis pela 'maior parte'

4 A Organização Mundial de Saúde (OMS) informa que os nomes oficiais são os seguintes: COVID-19, para referir a doença do coronavírus; e SARS-CoV-2, para o novo ou "segundo" coronavírus da síndrome respiratória aguda severa. do aquecimento 'inequívoco' da temperatura média global da Terra na segunda metade do século XX (Anderegg et al. 2010). De acordo com os dados referentes à elevação de $\mathrm{CO}_{2} \mathrm{e}$ gás metano $\left(\mathrm{CH}_{4}\right)$, a Terra elevaria a temperatura em $2^{\circ} \mathrm{C}$ ou $3^{\circ} \mathrm{C}$ nos próximos anos, com terríveis consequências, como a invasão de cidades costeiras pelo mar, devido à elevação do nível dos oceanos, em função do degelo no Ártico e na Antártida. Na sequência de relatórios produzidos e divulgados pelo IPCC, certas previsões apocalípticas foram mais tarde revistas, como a de que as geleiras de altitude dos Himalaias desapareceriam por completo até 2035. É importante observar que os relatórios do IPCC são elaborados com base na produção científica global, que, em sua grande maioria, apresentam estudos que alertam para a problemática relacionada às mudanças climáticas.

2. "O principal fator que influencia o clima da Terra seria o Sol, e não os gases atmosféricos". Na segunda posição, alguns cientistas até admitem a existência do aquecimento global, mas defendem que o processo é natural e que o aumento da atividade solar tenderia a causar um aumento médio da temperatura no planeta. A coalizão contesta a ameaça representada por gases-estufa e interpreta o $\mathrm{CO}_{2}$ como sendo benéfico, por estimular o crescimento da vegetação. Além disso, mesmo que fosse danoso ao meio ambiente, seu impacto não seria tão grave, pois a concentração do $\mathrm{CO}_{2}$ na atmosfera é inferior a $1 \%$.

3. "O aquecimento global não existe". A terceira coalizão pondera que o aquecimento global antropogênico, como hipótese, jamais foi provado; o "alarmismo", segundo essa corrente, constitui estratégia dos países desenvolvidos para evitar o aumento do consumo e melhoria do padrão de vida do mundo subdesenvolvido. Estariam presentes ainda outras questões políticas, totalmente desprovidas de valor científico. Como defensores da tese, citam-se Timoth Oke, climatólogo canadense, Ricardo Augusto Felício, professor e climatólogo da USP, Luiz Carlos Baldicero Molion, professor e meteorologista da Universidade Federal de Alagoas e o consultor britânico Lord Christopher Monckton (Hollingsworth, 2014). Há, inclusive, a afirmação de que a Terra possa se resfriar nos próximos anos, porque a atividade solar é cíclica (Oliveira, Vecchia \& Carneiro, 2017); sendo 
assim, os defensores dessa coalizão consideram que durante o período em que a atividade solar é mais intensa, as temperaturas aumentam e, quando ela diminui, as temperaturas abaixam, $\mathrm{o}$ que pode ocorrer nos próximos 20 ou 30 anos, porque "as nuvens ajudam a manter a Terra fresca, refletindo os raios do Sol, ao mesmo tempo em que a aquecem, conservando o calor" (Lomborg, 2012, p.333). As temperaturas, nessa perspectiva, só se elevariam em locais específicos, como os centros urbanos, em função das ilhas de calor. Os oceanos constituem a maior parte da superfície terrestre; assim, os estudos sobre sua influência sobre o clima oferecem revelações importantes sobre a relação entre a umidade do ar atmosférico e as temperaturas oceânicas. Pode-se citar a Oscilação Decadal do Pacífico, que vem influenciando o clima mundial (Pena, 2020).

Os embates argumentativos entre os que consideram o aquecimento global como resultado da ação do ser humano, e aqueles que reconhecem sua existência, mas o consideram como um processo natural e ainda os que defendem que o aquecimento sequer existe, confirmam a crítica de Esteves (2003) acerca da impossibilidade de concretização de um espaço público movido pelo consenso. Em vez disso, o espaço público se fragmenta e se dilui em posições dispersas. A comunicação pública torna-se, então, refém da intolerância ao argumento opositor (Oliveira et al., 2020, p.8).

Para evitar a corrosão da confiança nas informações que cada pessoa compartilha diariamente, é preciso adotar uma prática cotidiana de emprego de ferramentas de verificação de veracidade. $\mathrm{Na}$ medida em que a matriz da Advocacy Coalition leva em conta as diferentes coalizões formadas em torno de determinados temas, em uma perspectiva temporal da ordem de uma década ou mais, é preciso avaliar a veracidade daquilo que é veiculado pelas diferentes correntes em debate. Como fruto da restrição básica de que o debate precisa ser exclusivamente influenciado por fatos e informações realistas, a matriz ACF contrapõe os grupos antagônicos que divergem sobre o tema, buscando abranger a formulação e os padrões de mudança nas políticas públicas.

\section{Advocacy Coalition Framework}

A matriz da Advocacy Coalition é orientada pelo entendimento de que as políticas públicas nas sociedades contemporâneas são substantiva e legalmente complexas, envolvendo múltiplos atores, conflitos de metas, importantes disputas técnicas e variados níveis de governo, como ocorre com o aquecimento global antropogênico. O modelo ACF expande a análise para acadêmicos, jornalistas, agentes de variados níveis de governo e outros atores, desde que se tornem atores especializados e, portanto, de alguma forma potencialmente influentes na formulação e implementação de políticas (Weible, Sabatier \& McQueen, 2009).

A matriz ACF insere pesquisadores e os cientistas universitários, analistas políticos e consultores na lista de atores centrais em um processo de formulação política, pois assume que, durante intervalos da ordem de uma década ou mais, a informação científica e técnica exerce influência importante sobre as crenças dos participantes. Ao mesmo tempo, a concepção ACF reconhece que os atores tendem a se relacionar com o mundo por "um conjunto de filtros perceptivos compostos por crenças preexistentes", que são difíceis de alterar (Sabatier \& Weible, 2007, p.194), sendo provável o aparecimento de um quadro de desconfiança, porque atores de diferentes coalizões podem perceber a mesma informação de maneiras distintas.

O ACF começa com três "pedras fundamentais": (1) uma suposição de nível macro de que a maior parte da formulação de políticas ocorre entre especialistas dentro de um subsistema de política, cujo comportamento é afetado por fatores no sistema político e socioeconômico mais amplo; (2) um "modelo do indivíduo" de nível micro, fortemente inspirado na psicologia social; e (3) uma convicção de nível meso de que a melhor maneira de lidar com a multiplicidade de atores em um subsistema é agregá-los em "coalizões de defesa". Os fundamentos, por sua vez, afetam nossas variáveis dependentes, crença e mudança de política, por meio de dois caminhos críticos: aprendizagem orientada para políticas e perturbações externas (Sabatier \& Weible, 2007, p.191-192).

A formulação de políticas públicas ocorre em grande parte dentro de subsistemas que envolvem negociações entre especialistas; Sabatier (2007) assinala que, em um determinado escopo geográfico, cada subsistema reúne um conjunto de atores individuais ou coletivos de diversas organizações 
públicas, privadas e da sociedade civil (ONGs), ativamente preocupados com determinada questão de política pública e que regularmente tentam influenciar as decisões naquele domínio (Sabatier \& Jenkins-Smith, 1999). A matriz ACF concebe uma estrutura hierárquica composta de três níveis interligados: no nível mais abrangente estão núcleos de crenças profundas que perpassam a maioria dos subsistemas de política pública, como liberdade, igualdade etc., que são extremamente difíceis de mudar. No segundo nível situam-se os núcleos de crenças políticas, que lidam com escolhas políticas fundamentais, cujo escopo abrange todo o subsistema. Por essa razão, são igualmente difíceis de mudar. As crenças secundárias compõem o terceiro nível, cujo escopo é mais restrito, como por exemplo regras orçamentárias de um programa específico, a gravidade ou as causas de determinado problema em um local específico (Sabatier \& Weible, 2007). Desse modo, é mais fácil alterar as crenças secundárias, pois se exige menor intensidade de argumentação para convencer os atores do subsistema considerado.

\section{ACF nos embates sobre aquecimento global antropogênico}

A matriz ACF permite realizar uma análise abrangente das trocas argumentativas (Weible \& Sabatier, 2006, Weible, Sabatier \& McQueen, 2009) presentes na disputa relacionada ao aquecimento global antropogênico, possibilitando identificar os valores defendidos pelas coalizões. O ACF tenta mostrar de que forma agrupamentos concorrentes de grupos e indivíduos (advocacy coalitions) competem por políticas "vencedoras" em um determinado subsistema, usando estratégias políticas para afetar favoravelmente as decisões (Vicente \& Calmon, 2011), bem como informações técnicas e científicas para mudar pontos de vista de outras coalizões (Sabatier, 1988). O diagrama atualizado da Figura 2 fornece uma leitura das disputas em torno do aquecimento global, a partir das coalizões já anteriormente descritas.

O diagrama trabalha com o ambiente externo de um lado, dividido em parâmetros relativamente estáveis, que são reconhecidos em questões relacionadas aos impactos do aquecimento global no futuro, devido ao aumento da temperatura média dos oceanos e da atmosfera terrestre. Nos parâmetros relativamente estáveis também é possível reconhecer as diferentes percepções sobre o tema em função da distribuição de recursos naturais e clima regional, além da forte interferência dos interesses econômicos sobre políticas de meio ambiente. A relativa estabilidade em torno do tema também se manifesta na presença do Brasil no acordo climático e na Constituição Federal, que define a preservação do meio ambiente como uma questão pública, sendo de responsabilidade do poder público e de toda coletividade. O diagrama inclui no ambiente externo valores desafiadores, representados, no caso do aquecimento global, pela instabilidade econômica dos últimos anos, que gera questionamentos quanto a: (a) exigências de preservação ambiental junto aos setores que mais impactam o meio ambiente; (b) problemas de desemprego no Brasil, que geram pressões para flexibilização de controles de setores responsáveis por emissão de gases de efeito estufa; e (c) posturas contrárias ao impacto ambiental, com mobilização de milhões de pessoas ao redor do mundo preocupadas com o aquecimento global. Ao mesmo tempo, são desafiadoras as mudanças nas políticas públicas de meio ambiente de acordo com a composição governamental, ou a saída de países estratégicos como os EUA, recentemente revertida, do acordo do clima ou ainda a incapacidade dos países de fornecer compromissos e respostas concretas para enfrentar a emergência climática, sem contar a falta de vontade dos principais poluidores.

É importante lembrar que as setas que aparecem no diagrama explicitam relações de causalidade subjacentes ao modelo.

Na porção intermediária do diagrama aparecem as estruturas de oportunidade das coalizões de longo prazo, exemplificadas pela forte evidência científica, sistematicamente coletada desde os anos de 1990, que vem sendo apresentada à comunidade científica e à sociedade em geral, bem como a participação social mais restrita nas políticas públicas e o baixo nível de consenso. Ainda na zona intermediária são colocadas as limitações e recursos dos atores do subsistema que, no caso do aquecimento global, são indicados com: (a) o crescimento da percepção de que o aquecimento global é natural ou não existe; (b) a propagação de argumentos que consideram o aquecimento global uma estratégia dos países desenvolvidos para evitar o aumento do consumo pelo mundo subdesenvolvido, em busca de melhor padrão de vida; (c) estudos que enfatizam que a Terra pode se resfriar nos próximos anos; ou (d) dados que defendem que a atividade solar é cíclica, o que se reflete na alternância entre temperaturas mais quentes e mais frias; bem como (e) a demons-

\begin{tabular}{c|c|c|c|c|c|}
\hline (C) Terrae Didat. & Campinas, SP & v.17 & $1-11$ & $\mathrm{e} 021011$ & 2021 \\
\hline
\end{tabular}




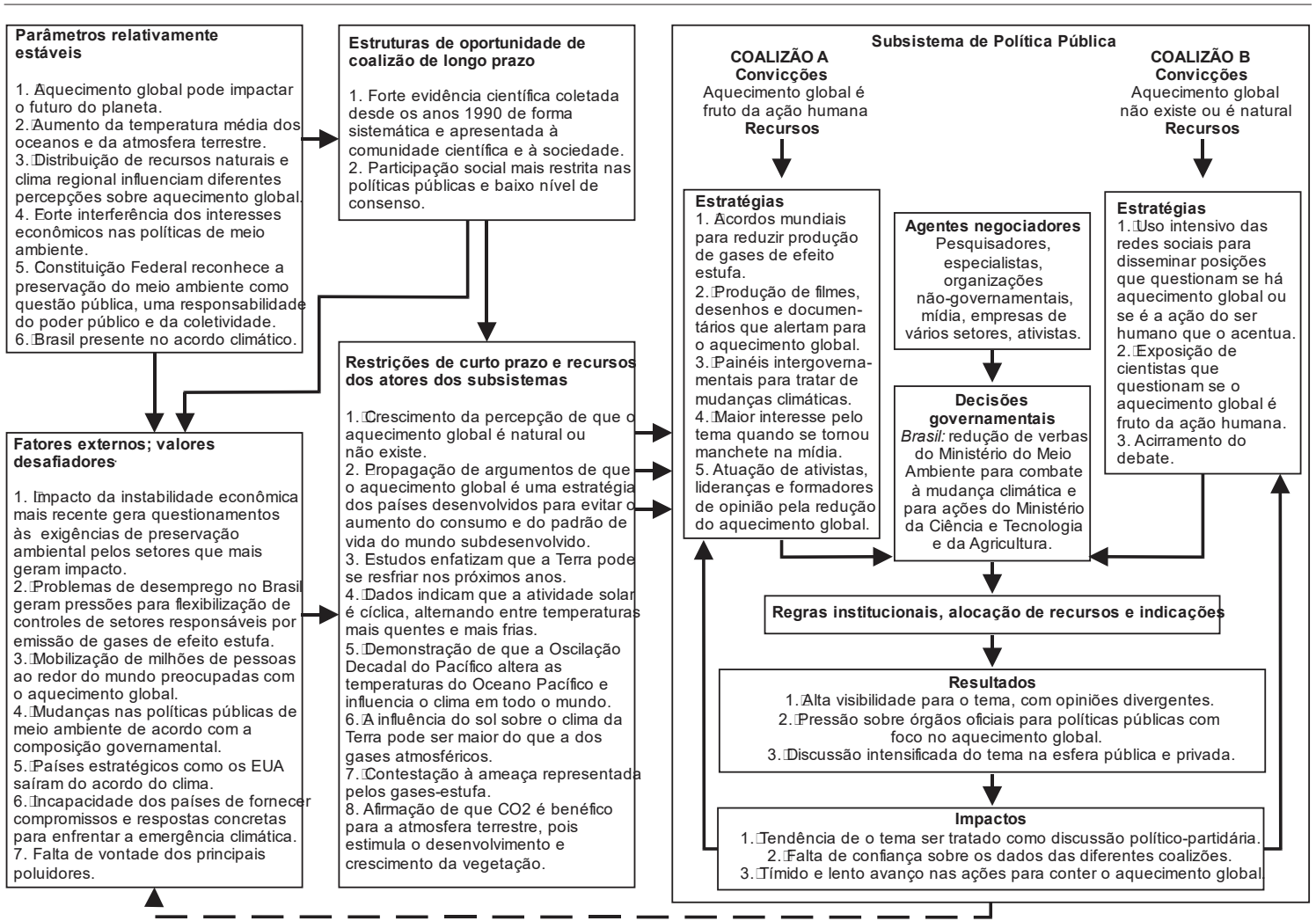

Figura 2. Diagrama da Advocacy Coalition Framework sobre o aquecimento global antropogênico. Fonte: Modificado de Sabatier Weible (2007, p. 202)

tração de que a Oscilação Decadal do Pacífico altera as temperaturas do Oceano Pacífico e influencia o clima em todo o mundo. Alguns atores também recorrem a estudos que revelam a firme influência do Sol sobre o clima da Terra, que pode ser maior do que a dos gases atmosféricos ou se contrapor às contestações sobre a ameaça dos gases-estufa. Além disso, alguns atores ponderam que o $\mathrm{CO}_{2}$ é benéfico para a atmosfera terrestre, pois estimula o desenvolvimento e crescimento da vegetação.

Do outro lado do diagrama está o subsistema de políticas públicas, em que constam as posições das diferentes coalizões em conflito. Para simplificar, classificamos apenas dois grandes grupos de coalizões. A coalizão A representa o grupo que defende que o aquecimento global é fruto da ação do ser humano e que apresenta como estratégias de defesa a assinatura de acordos mundiais para reduzir a produção dos gases que aumentam o efeito estufa; a produção de filmes, desenhos e documentários que alertam para o aquecimento global; os painéis intergovernamentais para tratar de mudanças climáticas; a valorização do tema pela mídia; e a atuação de ativistas, lideranças e formadores de opinião pública em prol de ações que reduzam o aquecimento global.
Já a coalizão B representa tanto os que defendem que o aquecimento global não existe, como aqueles que entendem ser mero processo natural. Nesse caso, as redes sociais são intensivamente usadas como estratégia de disseminação de posições que questionam se existe aquecimento global ou se é a ação do ser humano que o acentua; envolve ainda a exposição de alguns cientistas que questionam se o aquecimento global é, de fato, fruto da ação humana, até mesmo com acirramento crescente do debate.

Em meio às coalizões emergem os agentes negociadores, representados por pesquisadores, especialistas, organizações não-governamentais, veículos de mídia, empresas de diversos setores, ativistas que pressionam as decisões das autoridades governamentais. No embate entre coalizões, um dos lados ganha força no Brasil com a redução de verba do Ministério do Meio Ambiente para o combate à mudança climática, ainda que algumas ações estejam sendo conduzidas pelos ministérios da Ciência e Tecnologia e da Agricultura. Mesmo assim, o resultado expresso no diagrama, de acordo com a análise realizada pelos autores, revela que, apesar das divergências de opinião, o tema ganhou visibilidade. Reconhece-se a crescente pressão sobre 
os órgãos oficiais para políticas públicas com foco no aquecimento global e a discussão mais intensificada do tema nas esferas pública e privada, além de identificar o impacto gerado pelas diferentes coalizões. Muitas vezes elas não estão dispostas ao diálogo, até mesmo porque o tema parece se confundir com uma discussão político-partidária. Falta confiança quanto aos dados apresentados pelas diferentes coalizões, em meio a tantas notícias falsas, o que conduz a um tímido e lento avanço nas ações para conter o aquecimento global caso, evidentemente, a humanidade disponha dos meios efetivos para tanto.

Finalmente, chegamos à questão educacional, pois um componente relevante da missão do professor relaciona-se a interferir ou mediar a "construção do conhecimento científico" (Martins, 2014, p.127). Muitos professores não se sentem confortáveis para se aprofundar no tema AGA com seus alunos, quer pela escassez de materiais didáticos, quer pela restrita bagagem conceitual de que dispõem para optar por uma das narrativas que inevitavelmente conhece. No ensino de Geociências, as controvérsias e problematizações podem induzir nos alunos uma inquietação epistemológica, que estimula o aprendizado pelo questionamento de conhecimentos previamente aprendidos (Martins, 2014). Ao iluminar de modo mais claro os argumentos de cada coalizão (Fig. 2), a matriz ACF contribui para compor um quadro transdisciplinar e para estimular uma visão crítica dos embates e dos argumentos das correntes em disputa.

\section{Considerações finais}

A discussão sobre o aquecimento global antropogênico pode exemplificar o impacto direto que a comunicação, envolvendo a manifestação de opiniões diversas, pode provocar em questões sobre sustentabilidade. A aplicação da matriz de Advocacy Coalition Framework (ACF) permitiu entender de que forma coalizões concorrentes utilizam estratégias políticas e de comunicação, e ao mesmo tempo compartilham informações técnicas e científicas, para afetar decisões e mudar pontos de vista em relação ao aquecimento global antropogênico. A preocupação com a densidade argumentativa das manifestações sobre o tema exige atenção por se tratar de objeto de interesse público, principalmente frente à fragilidade de discursos respaldados em notícias falsas, porque estas geram prejuízos à sociedade, ao meio ambiente e à própria qualidade democrática. Esta última deve ser pautada em uma discussão capaz de gerar consciência e razão. Sobressaem, portanto, no debate, os mecanismos indispensáveis de identificação de notícias falsas, que fragilizam o debate e jamais podem se confundir com a incerteza, que é um componente inerente à Ciência. Ao analisar as várias coalizões e as respectivas argumentações sobre o tema, enfatiza-se a vulnerabilidade das trocas argumentativas baseadas em Fake News, que, no limite, descontroem e desqualificam a própria democracia.

Tendo a teoria de Chantal Mouffe para justificar um cenário com pouca propensão ao consenso, já que as coalizões que se formam em torno do tema se colocam na posição do típico antagonismo "nós/ eles", é possível ter uma percepção de que, mesmo assim, vivemos uma democracia em estágio diverso daquele que poderia ser analisado exclusivamente com base na teoria habermasiana e que ainda requer avançar do antagonismo para o agonismo.

A comunicação pública, na perspectiva aqui analisada, pode ser definida como espaço da diversidade de opiniões sobre temas de interesse público, cujos atores expressam-se por trocas argumentativas, sob diferentes perspectivas, que visam influenciar políticas públicas. Espera-se que esta nota possa delinear novos desmembramentos, levantamentos e análises empíricas que comprovem, na prática, o impacto da Comunicação Pública da Ciência nas políticas públicas de sustentabilidade, mesmo quando as coalizões em conflito estiverem ainda muito distantes de qualquer consenso, como parece ser o caso do AGA.

\section{Agradecimentos/Apoio}

O autor C. D. R. Carneiro agradece ao $\mathrm{CNPq}$ (Conselho Nacional de Desenvolvimento Científico e Tecnológico) pela concessão de bolsa de produtividade em pesquisa, nível 2.

\section{Referências}

Anderegg, W. R. L., Prall, J. W. Harold, J. \& Schneider S. H. (2010). Expert credibility in climate change, PNAS July 6, 2010, 107(27), 12107-12109. doi: 10.1073/pnas.1003187107.

Caldas, G. (2004). Comunicação Pública e Ciência Cidadã. In: Oliveira, M. J. C. (org.). (2004). Comunicação Pública. Campinas: Alínea. p. 29-47.

Carneiro, C. D. R., \& Toniolo, J. C. (2012). A Terra 'quente' na imprensa: confiabilidade das notícias sobre aquecimento global. Revista Hist. cienc. saudeManguinhos [online], 19(2), 369-389. (abr.-jun. 2012). 
URL: http://www.scielo.br/pdf/hcsm/v19n2/02.pdf. Acesso 18.jun.2015.

Carneiro, C. D. R., Freitas, G. B. F. de, Franco, L. M., \& Gonçalves, P. W. (2018). O que a Pequena Idade do Gelo pode nos ensinar sobre mudança climática? In: Carneiro, C. D. R., Gonçalves, P. W., Imbernon, R. A. L., Machado, F. B., \& Cerri, C. A. D. (Eds.). (2018). Ensino e História de Ciências da Terra. Campinas: Soc. Bras. Geol. p. 260-265. URL: http://www. ige.unicamp.br/geoscied2018/pt/trabalhos/. (Anais VIII Simp. Nac. Ens. Hist. Ciências da Terra / EnsinoGEO-2018 - Geociências para todos. Campinas, SBGeo, 2018).

Carneiro, C. D. R., Freitas, G. B. F. de, Franco, L. M., Gonçalves, P. W. (2020). A Pequena Idade do Gelo: evidências históricas e geológicas de mudanças climáticas. Belo Horizonte: Geonomos, 28(1), 47-63. (no prelo).

Castells, M. (2000). Fim do Milênio. São Paulo: Paz e Terra.

Castells, M. (2009). Comunicácion y poder. Trad. Maria Hernández. Madrid: Alianza Editorial. 679p. URL: https://el.b-ok.cc/book/2193329/9d96e5. Acesso 05.01.2021.

Esteves, J. P. (2003). Espaço Público político. In: Esteves, J. P. (2003). Espaço público e democracia: comunicação, processo de sentido e identidade social. São Leopoldo, Unisinos.

Freire, P. (1975). Extensão ou Comunicação? Trad. Rosisca Darcy de Oliveira. Rio de Janeiro: Paz e Terra.

Germano, M. G., \& Kulesza, W. A. (2007). Popularização da Ciência: uma revisão conceitual. Cad. Bras. Ens. Fís., 24 (1), 7-25. doi: 10.5007/\%25x.

Gozetto, A., \& Machado, L. (2015). Ainda é preciso esclarecer conceitos: Lobby X Advocacy. Cause. Publ. 14.out.2015. URL: http://www.cause.net.br/ainda-e-necessarioesclarecer-conceitos-lobby-x-advocacy/. Acesso 16.03.2021.

Habermas, J. (2008). Consciencia moral y acción comunicativa. Trad. Ramón Cotarelo García. Madrid: Editorial Trotta.

Hernando, M. C. (2005). Divulgacao cientifica: um grande desafio para este século. Entrevista. São Paulo:Cienc. Cult., 57(2). URL: http://cienciaecultura.bvs.br/scielo.php?script $=$ sci_arttext\&pid =S0009-67252005000200013. Acesso 05.01.2021.

Hollingsworth, B. (2014). Monckton: Political Danger Rises As Evidence of Global Warming Declines. CNSNews. com. 07.07.2014. URL: https://www.cnsnews.com/ news/article/barbara-hollingsworth/moncktonpolitical-danger-rises-evidence-global-warmingdecline-0. Acesso 10.01.2021.

Intergovernmental Panel of Climatic Change (IPCC) (2013). Climate Change 2013: The Physical Science Basis. Contribution of Working Group I to the Fifth Assessment Report of the Intergovernmental Panel on Climate Change [Stocker, T.F., D. Qin, G.-K. Plattner, M. Tignor, S.K. Allen, J. Boschung, A. Nauels, Y.
Xia, V. Bex and P.M. Midgley (eds.)]. Cambridge, United Kingdom and New York, NY, USA, Cambridge University Press. 1535p. doi: 10.1017/ CBO9781107415324.

Jaramillo López. J. C. (2011a). Advocacy: uma estratégia de comunicação pública. In: Kunsch, M. M. K. (org.). (2011a). Comunicação pública, sociedade e cidadania. São Caetano do Sul: Difusão. p. 61-80.

Lindley, D. V. (2006). Understanding Uncertainty. New York: Wiley-Interscience. 250p.

Lomborg, B. (2002). O ambientalista cético. Revelando a real situação do mundo. 3 ed. Trad. Ivo Korytowski, Ana B. Rodrigues. Rio de Janeiro: Elsevier. 541p.

Loon, A. J. van. (1999). The meaning of "abrupteness" in the geological past. Earth Science Reviews, 45(3-4), 209-214. doi: 10.1016/S0012-8252(99)00005-7.

Marrafon, V. H., \& Reboita, M. S. (2020). Características da precipitação na América do Sul reveladas através de índices climáticos. Revista Brasileira de Climatologia, 26, 663-676. URL: https://revistas.ufpr.br/revistaabclima/article/view/72181/40775. Acesso 17.02.2021.

Martins, J. R. S. (2014). Controvérsias e problematização no ensino de Geociências. Tese (Doutorado). Campinas, SP, Programa de Pós-Graduação em Ensino e História de Ciências da Terra (PEHCT), Instituto de Geociências, Universidade Estadual de Campinas. 151p. URL: http://repositorio.unicamp.br/handle/REPOSIP/286640.

Martins, J. R. S. (2014). Controvérsias e problematização no ensino de Geociências. Tese (Doutorado). Campinas, SP, Programa de Pós-Graduação em Ensino e História de Ciências da Terra (PEHCT), Instituto de Geociências, Universidade Estadual de Campinas. URL: http://repositorio.unicamp.br/handle/ REPOSIP/286640.

Martins, L., Bonito, J., Marques, L., \& Carneiro, C. D. R. (2015). Desenvolvimento sustentável: algumas linhas de ação para a Amazónia. Boa Vista: Olhares Amazônicos, 4(1), 700-719. URL: http://ufrr. br/roa/index.php/21-volume-4-numero-1. Acesso 16.02.2021.

Matos, H. (2006). Comunicação Política e Comunicação Pública. São Paulo, ECA-USP: Comunicação pública e governamental, 3(4). (Dossiê). doi: 10.11606/ issn.2238-2593.organicom.2006.138911.

Matos, H. (org.) (2013). Comunicação pública: interlocuções, interlocutores e perspectivas. São Paulo: ECA/São Paulo: ECA/USP. 288p. URL: http://www3.eca.usp.br/ sites/default/files/form/biblioteca/acervo/producaoacademica/002436283.pdf. Acesso 10.01.2021.

Monteiro, R. A., Santos, R. L. S., Pardo, T. A. S., Almeida, T. A. de, Ruiz, E. E. S., \& Vale, O. A. (2018). Contributions to the Study of Fake News in Portuguese: New Corpus and Automatic Detection Results. São Carlos, Núcleo Interinstitucional de Linguística Computacional (NILC), Universidade de São Paulo (USP). URL: https://sites.icmc.usp.br/taspardo/PROPOR2018- 
MonteiroEtAl.pdf. Acesso 22.12.2020.

Morozov, E. 2011. The net delusion: the dark side of Internet freedom. New York: PublicAffairs. 408p.

Mouffe, C. (2015). Sobre o Político. São Paulo. Martins Fontes.

Oliveira, M. J. C. (2013). Comunicação organizacional e comunicação pública. In: Matos, H. (org.) (2013). Comunicação pública: interlocuções, interlocutores e perspectivas. São Paulo: ECA/USP.p. 15-28. URL: http:// www3.eca.usp.br/sites/default/files/form/biblioteca/ acervo/producao-academica/002436283.pdf. Acesso 10.01.2021.

Oliveira, M. J. C., \& Miotto, L. B. (2018). Vida sustentável e comunicação: O diálogo necessário entre Estado, mercado e sociedade civil. Curitiba, Appris.

Oliveira, M. J. C., Nobre, H. M. e, Barbosa, R. (2020). Comunicação pública entre o consenso e o antagonismo dos discursos sobre aquecimento global. O impacto para políticas públicas de sustentabilidade. Bauru, SP, Abrapcorp. XIV Congr. Bras. Científico de Comunicação Organizacional e de Relações Públicas, 18 a 21/05/2020. URL: $\quad$ http://abrapcorp.org.br/site/manager/ arq/1ydnvPljFC_FINAL-Artigo.Abrapcorp.2020TEMPLATE-COM-AUTORIA_GT_2020.pdf. Acesso 05.01.2021.

Oliveira, M. J. de, Carneiro, C. D. R., Baptista, G. M. M., \& Vecchia, F. A. S. 2017. Ciclos climáticos e causas naturais das mudanças do clima. Terre Didatica. 13(3), 149-184. doi: 10.20396/td.v13i3.8650958.

Oliveira, M. J. de, Vecchia, F. A. S., \& Carneiro, C. D. R. 2015. A educação no contexto do aquecimento global: da ignorância e analfabetismo científico ao raciocínio crítico e literacia climática. Periódico Eletrônico Fórum Ambiental da Alta Paulista, 11(4), 287-310. (Anais Fórum Ambiental da Alta Paulista, 11, Tupã, 20 a 22 de julho de 2015. Anais..., Tupã, UNESP, Campus de Tupã). doi: 10.17271/1980082711420151292.

Pena, R. F. A. (2020). Análises científicas suscitam a dúvida: o Aquecimento Global existe ou não? Mundo Educação. URL: https://mundoeducacao.bol.uol.com.br/ geografia/aquecimento-global-existe-mesmo.htm. Acesso 22.12.2020.

Reboita, M. S., Marrafon, V. H., Llopart, M., \& Rocha, R. P. da. (2018). Cenários de mudanças climáticas projetados para o Estado de Minas Gerais. Revista Brasileira de Climatologia, Ano 14, 110-128. (Ed. Esp. Dossiê Climatologia de Minas Gerais). doi: 10.5380/ abclima.v1i0.60524.

Robinson, M., \& Dowsett, H. (2010). Why study paleoclimate? U.S. Geological Survey, Fact Sheet 20103021. URL: http://pubs.usgs.gov/fs/2010/3021/pdf/ fs2010-3021.pdf. Acesso 10.01.2021.

Sabatier, P. A, Weible, C. M. (2007). The advocacy coalition framework: Innovations, andclarifications. In: Sabatier, P. A (Ed.). (2007). Theories of the Policy Process. 2 ed. Boulder: Westview Press. p. 189-220.
(Chapter 7).

Sabatier, P. A. (1988). An Advocacy Coalition Framework of policy change and the role of policy-oriented learning therein. Policy Sciences, 21, p.129-168.

Sabatier, P., Jenkins-Smith, H. (1999). The advocacy coalition framework: An assessment. In: Sabatier, P.A. (Ed.). Theories of the Policy Process. Boulder: Westview Press. p. 117-166.

Santos, M. F., \& Fonseca, T. B. (2019). "Falando Grego": o caso \#EXISTEPESQUISANOBR como tentativa de divulgação da ciência. In: Matos, H., \& Gil, P. (orgs.) (2019). Comunicação, Políticas Públicas e Discursos em Conflito. São Paulo, ECA/USP. p. 279-319.

Silva, Silva, M. V. da. (2008). Conhecimento, Educação, Sociedade. Brasília, UnB: Revista de Letras, 1(1). URL: https://portalrevistas.ucb.br/index.php/RL/ article/view/26. Acesso 05.01.2021.

United Nations Organization (UN). (1987). Report of the World Commission on Environment and Development: Our common future. Oslo, Norway, A/42/427. (Annex) URL: http://www.channelingreality.com/ Documents/Brundtland_Searchable.pdf. Acesso 16.02.2021.

United Nations Organization (UN). Department of Economic and Social Affairs (DESA). Division for Sustainable Development Goals (DSDG) (2015). Transforming our world: the 2030 Agenda for Sustainable Development. United Nations. URL: https://sustainabledevelopment.un.org/post2015/transformingourworld. https://sustainabledevelopment.un.org/ post2015/transformingourworld/publication. Acesso 16.02 .2021 .

United Nations Organization (UN). Department of Economic and Social Affairs (DESA). (s.d.). The 17 Goals. United Nations. URL: https://sdgs.un.org/ goals. Acesso 16.02.2021.

Vicente, V. M. B., \&Calmon, P. C. D. P. (2011). A Análise de Políticas Públicas na Perspectiva do Modelo de Coalizões de Defesa. In: XXXV Encontro da Anpad, Rio de Janeiro, 4-7.09.2011. p. 01-15. URL: http:// www.anpad.org.br/admin/pdf/APB2163.pdf. Acesso 20.12.2020.

Vilaça, W. P. T. (2012). A Comunicação Interna na gestão da sustentabilidade: um estudo fenomenológico. São Paulo, ECA-USP. (Tese Dout.).

Weible, C. M., \& Sabatier, P. A. (2006). A Guide to the Advocacy Coalition Framework. In: Fisher, F., Miller, G. J. (Eds.) (2006). Handbook of Public Policy Analysis.Boca Raton, London, New York:CRC Press. P. 123-136. (Cap. 9). URL: https://www.academia.edu/6247912/Handbook_of_Public_Policy_ Analysis?auto = download. Acesso 22.12.2020.

Weible, C. M., Sabatier, P. A., \& McQueen, K. (2009). Themes and Variations: Taking Stock of the Advocacy Coalition Framework. The Policy Studies Journal, 37(1), 121-140. doi: 10.1111/j.15410072.2008.00299.x. 